\title{
Voltammetric study of cefotaxime at the macroscopic and miniaturized interface between two immiscible electrolyte solutions
}

\author{
Konrad Rudnicki ${ }^{1}$ - Karolina Sobczak ${ }^{1} \cdot$ Magdalena Kaliszczak $^{2} \cdot$ Karolina Sipa $^{1}$ - Emilia Powałka ${ }^{1}$. \\ Sławomira Skrzypek ${ }^{1} \cdot$ Lukasz Poltorak $^{1} \cdot$ Gregoire Herzog $^{2}$
}

Received: 16 September 2021 / Accepted: 17 October 2021 / Published online: 9 November 2021

(c) The Author(s) 2021

\begin{abstract}
The electrochemical behavior of cefotaxime $\left(\mathrm{CTX}^{+}\right)$was investigated at the polarized macro- and micro-interface between two immiscible electrolyte solutions (ITIES) by cyclic voltammetry and alternating current voltammetry. Miniaturization was achieved with fused silica microcapillary tubing entrapped in a polymeric casing. Scanning electron microscopy (SEM) was employed for the fabricated LLI support characterization. Voltammetric investigation of $\mathrm{CTX}^{+}$at macro- and $\mu$-ITIES allowed the determination of many physicochemical parameters, such as formal Galvani potential of the ion transfer reaction $\left(\Delta_{o r g}^{a q} \Phi^{\prime}\right)$, diffusion coefficients $(D)$, formal free Gibbs energy of the ion transfer reaction $\left(\Delta G^{\prime a q \rightarrow o r g}\right)$, and water-1,2-dichloroethane partition coefficient $\left(\log P_{\text {water } / D C E}^{C T X+}\right)$. Additionally, based on the results obtained the analytical parameters including voltammetric sensitivity, limits of detection and the limits of quantification (in micromolar range) were calculated. The applicability of the developed procedures was verified in spiked still mineral and tap water samples.
\end{abstract}

Keywords ITIES $\cdot$ Electrified liquid-liquid interface $\cdot$ Fused silica capillaries $\cdot$ Cefotaxime $\cdot$ AC voltammetry

\section{Introduction}

Cephalosporins (CFS) are semi-synthetic antibiotics of the $\beta$-lactam family. Their mechanism of action is based on the reduction of bacterial peptidoglycans consequently blocking their growth [1]. These antibiotics have a broad spectrum of activity against Gram-positive and Gram-negative aerobic and anaerobic bacteria. Cefotaxime (CTX, Fig. 1C) is the most active among third-generation CFS, particularly against Gram-negative bacteria as compared with the 1st

Konrad Rudnicki

konrad.rudnicki@chemia.uni.lodz.pl

Lukasz Poltorak

lukasz.poltorak@chemia.uni.lodz.pl

$\triangle$ Gregoire Herzog

gregoire.herzog@univ-lorraine.fr

1 Department of Inorganic and Analytical Chemistry, Faculty of Chemistry, University of Lodz, Tamka 12, 91-403 Lodz, Poland

2 Université de Lorraine, CNRS, LCPME, Nancy, France and 2nd CFS generations [2]. In humans, these antibiotics are often used to treat urinary and respiratory tract bacterial infections. Preventive treatment of bacterial infections in cattle with CFS is a direct threat of their residues in food, especially meat and dairy products [3]. Antimicrobial resistance of bacteria together with the potential allergic reactions caused by $\mathrm{CTX}^{+}$along with other members of $\beta$-lactam family are certainly a societal problem. In recent years, the consumption of antibiotics has increased dramatically leading their existence in natural environment. Especially due to this reasons, these chemical species must be monitored in the surrounding environments, human and animal biological fluids, or foodstuffs [2, 4].

A number of methods have been reported to date for the determination of $\mathrm{CTX}^{+}$. Examples include high-performance liquid chromatography (HPLC) [5, 6], liquid chromatography (LC) [7], chemiluminescence sensing [8], and also electroanalytical methods $[4,9,10]$. Low cost, simple instrumentation, existence of relatively easy miniaturization protocols, and integrability into electronic circuits speak for electrochemical techniques which are especially attractive from the presumptive sensing point of view. Electroanalytical 
Fig. 1. A Cyclic voltammograms (CVs) recorded for blank (0) and increasing $\mathrm{CTX}^{+}$concentration (1-10) equal to 21.4; 42.7; 70.9; 140.8; 209.8; 277.8; $411.1 ; 540.5 ; 666.7$ and 909.1 $\mu \mathrm{M}$. The aqueous phase was 10 $\mathrm{mM} \mathrm{HCl}(\mathrm{pH}$ 2). B The corresponding forward (positive) and backward (negative) peak current intensities plotted in function of the $\mathrm{CTX}^{+}$concentration. $\mathbf{C}$ The inset presents the structure of $\mathrm{CTX}^{+}$. Conditions: $v=20 \mathrm{mV} \mathrm{s}^{-1}$.

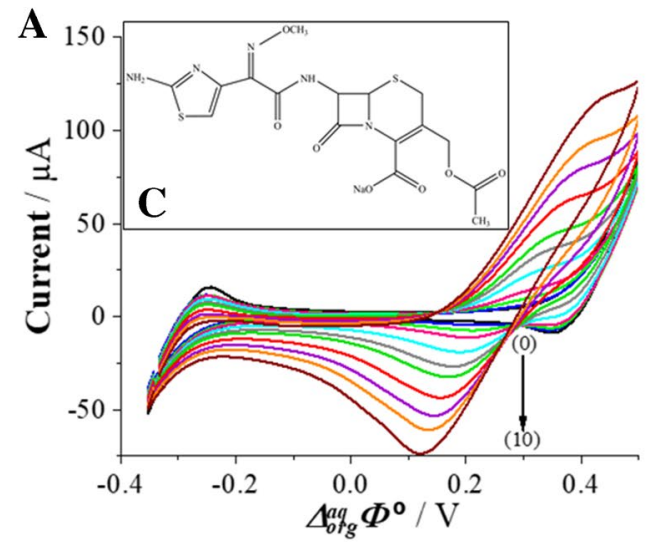

sensing at solid electrodes can reach high or even very high selectivity usually for the cost of the elaborated surface engineering [11]. Detection of different chemical species, such as $\mathrm{CTX}^{+}$, at the solid electrodes, can be obstructed by the redox active interferences co-existing in real samples. (e.g., phenols passivating carbon-based electrodes are inactive at the ITIES when deprived from other ionizable functionalities) [12].

Electrochemistry at the interface between two immiscible electrolyte solutions (ITIES) provides an alternative to a conventional sensing at the solid electrified junctions [13]. Detection at ITIES is not limited to oxidation/reduction reactions; its mechanism is frequently related to ionic species transferring across the polarizable liquid-liquid interface (LLI). It is often used to detect charged molecules that are electrochemically inactive at conventional solid electrodes [14]. Moreover, since the ionic partitioning governed by the molecular lipophilicity is directly related to the Galvani potential difference of the ion transfer reaction, the signals originating from hydrophilic-hydrophobic analytes can be separated which in turn may improve detection selectivity. For all these reasons, ITIES was used to study many classes of chemical species, e.g., proteins [15], antibiotics [16], drugs [17], or polyelectrolytes [18].

Within last two decades, significant attention was given to the development of a variety of ITIES miniaturization protocols [19]. LLI downscaling brings a few benefits to electroanalytical studies. First of all, under proper geometrical conditions, the mass transfer of the analyte towards the microscopic junction is improved as compared with the macroscopic systems. This in turn improves the detection sensitivity. Capacitive currents drop with the ITIES surface area further lowering the voltammetric limits of detection. Small internal volumes of the miniaturized ITIES platforms drastically reduce amount of consumed reagents, especially toxic organic phase [16]. Finally, the properties of the miniaturized ITIES can be tuned by the surface chemistry of the supports. Lisiqi Xie et al. constructed nanoITIES formed within an ultrathin (80 $\mathrm{nm}$ thickness) isoporous silica membrane patterned with channels having 2-3 $\mathrm{nm}$ as the inner diameter and showed that the interfacial transfer of model ions was affected by the membrane surface charge controlled by the aqueous phase $\mathrm{pH}$ [20]. Size and charge sieving at the ITIES can be also achieved with silica deposits [21] or charged polymeric cushions [22]. The examples of other platforms used as an ITIES support include laser ablated pore(s) formed within polymeric [23] films or glass sheets [15], ion beam patterning of silicon nitride wafers [24], etched metal microwire electrodes formed in a glass casing [25], or pulled glass capillaries [26]. All these examples require the access to fabrication facilities and are burthen with rather timely preparation procedures. We have recently proposed a very fast $\mu$ ITIES fabrication protocol which uses fused silica micro-capillaries having $25 \mu \mathrm{m}$ as an inner diameter. We have found that these platforms can be successfully used for electroanalytical applications, e.g., fluoroquinolone antibiotics screening [16, 27], food quality control [14], or as a support to electrochemically facilitated formation of nylon-6,6 at the ITIES [28].

In this work, we have miniaturized the ITIES formed at the water || 1,2-dichloroethane solutions to study interfacial behavior of one of the CFSs antibiotics - cefotaxime. Cyclic voltammetry (CV) allowed the determination of a number of electroanalytical and physicochemical parameters, e.g., formal Galvani potential of the ion transfer reaction $\left(\Delta_{\text {org }}^{a q} \Phi^{\prime}\right)$, diffusion coefficients $(D)$, formal free Gibbs energy of the ion transfer reaction $\left(\Delta G^{\prime a q \rightarrow o r g}\right)$, and water1,2-dichloroethane partition coefficient $\left(\log P_{\text {water } / D C E}^{C T X+}\right)$. We also applied alternating current voltammetry (ACV) to study $\mathrm{CTX}^{+}$in model and spiked real mineral water and tap water. The obtained results were validated and analytical parameters, this is limits of detection (LOD), limits of quantification (LOQ), linear dynamic range (LDR), and detection sensitivities were tabulated. 


\section{Methods and materials}

\section{Apparatus}

All electroanalytical measurements were carried out with the AUTOLAB-PGSTAT302N) equipped with the ECD module (Metrohm Autolab B.V., the Netherlands) controlled via NOVA 1.11.1 software. MacroITIES studies were performed in a four-electrode electrochemical system equipped with two platinum $(\mathrm{Pt})$ wires acting as the counter electrodes and two silver/silver chloride wires $(\mathrm{Ag} / \mathrm{AgCl})$ applied as the reference electrodes (Scheme 1). The formal Galvani potential of the ion transfer was calculated using data from cyclic voltammograms with the potential axis calibrated using standard Galvani potential of tetrapropylammonium cation $\left(\Delta_{\text {org }}^{a q} \Phi_{T P r A^{+}}^{0}=-0.091 V\right)[29]$.

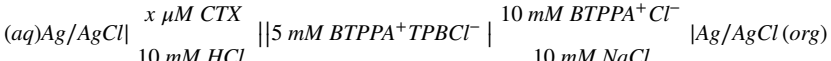

The set-up used for $\mu$ ITIES polarization contained three electrodes, two in the aqueous phase and one in the organic phase. In the aqueous phase, the platinum wire (Pt) and silver/silver chloride wire $(\mathrm{Ag} / \mathrm{AgCl})$ were employed as the counter and reference electrode, respectively. In the organic phase, the platinum wire (Pt) was used as the auxiliary and the pseudo-reference electrode (Scheme 2). The $\mu$ ITIES system was constructed using a small piece of methyl deactivated (internal walls of the tubing are commercially functionalized with methyl groups) fused silica microcapillary tubing (FSMT) with inner diameter $=25 \mu \mathrm{m}$. The fabrication protocol of $\mu$-platforms preparation is described elsewhere [27].

(aq)Ag/AgCl| $\begin{gathered}x \mu M C T X \\ 10 \mathrm{mM} \mathrm{HCl}\end{gathered}\left|10 \mathrm{mMBTPPA^{+ }} \mathrm{TPBCl}^{-}\right| \mathrm{Pt}($ org $)$

$\mathrm{AC}$ voltammetry measurements were performed under the following experimental conditions: frequency $(f) 1 \mathrm{~Hz}$, the amplitude $(E)=10 \mathrm{mV}$ and the step potential $(\Delta E)=$ $10 \mathrm{mV}$. It was assumed that the $\mu$ ITIES system behaves as a Randles circuit. The analytical signal $(\Upsilon)$ applied to plot the AC voltammograms was obtained according to Eq. (1) [30]:

$\Upsilon=-\frac{10^{6}}{\omega Z_{I m} a}-C_{d}$

where $\omega$, the angular frequency $\left(\mathrm{rad} \cdot \mathrm{s}^{-1}\right) ; Z_{I m}$, the imaginary part of the impedance; $a$, the surface of the polarized LLI $\left(a=1.39 \mathrm{~cm}^{2}\right)$; and $C_{d}$, the double layer capacitance of the polarized LLI.

All measurements were conducted at room temperature $\left(21.0 \pm 2.0^{\circ} \mathrm{C}\right)$.

The characterization of the FSMT used to fabricate $\mu$ ITIES platforms was performed with a scanning electron microscope (SEM, JCM-6000 Versatile Benchtop, JEOL, Japan). The beam energy of $5 \mathrm{kV}$ was applied.

\section{Reagents and solutions}

All solutions used in this work were prepared from analytical grade chemicals. Analytical standard of $\mathrm{CTX}^{+}$(CAS No. 64485-93-4) was purchased from Sigma-Aldrich (France). CTX ${ }^{+}$fresh stock solution $(10 \mathrm{mM})$ was freshly prepared in $10 \mathrm{~mL}$ glass graduated flask by dissolving an appropriate amount of analyte in $10 \mathrm{mM}$ hydrochloric acid ( $\mathrm{HCl})$ solution. Potassium tetrakis(4-chlorophenyl)borate (KTPBCl, > 98\%) and bis(triphenylphosphoranylidene) ammonium chloride (BTPPACl, 97\%) were also purchased from Sigma-Aldrich (France) and were used as the substrates fora bis(triphenylphosphoranylidene)ammonium tetrakis(4-chlorophenyl)borate (BTPPATPBCl) synthesis. Self-made BTPPATPBCl was dissolved in 1,2-dichloroethane (1,2-DCE, 99\% Sigma-Aldrich, France) and was subsequently used as the supporting electrolyte for the organic phase. The tetramethylammonium chloride (TMACl, 97\%, Sigma-Aldrich, France) was employed as a reference and model species. All aqueous solutions were prepared using deionized water, filtered using $0.22-\mu \mathrm{m}$ filters (Millipore) and refrigerated at $\pm 4.0^{\circ} \mathrm{C}$. The FSMT with an internal diameter of $25 \mu \mathrm{m}$ was obtained from VWR (Poland).

$$
\begin{gathered}
\text { (aq) } \mathrm{Ag} / \mathrm{AgCl} \\
\left.\begin{array}{c}
x \mu \mathrm{MCTX} \\
10 \mathrm{mM} \mathrm{HCl}
\end{array}|| 5 \mathrm{mM} \mathrm{BTPPA} \mathrm{TPBCl}^{-}\right|^{10 \mathrm{mM} \mathrm{BTPPA} \mathrm{Cl}^{-}} \\
10 \mathrm{mM} \mathrm{NaCl}
\end{gathered} \mid \mathrm{Ag} / \mathrm{AgCl} \text { (org) }
$$

Scheme 1. The composition of the cell used to study the electrochemical behavior of $\mathrm{CTX}^{+}$at the macroITIES.

Scheme 2. Electrochemical cell employed in $\mu$ ITIES studies.

$$
\text { (aq)Ag/AgCl| } \begin{gathered}
x \mu M C T X \\
10 \mathrm{mM} \mathrm{HCl}
\end{gathered}|| 10 \mathrm{mMBTPPA} \mathrm{mPBCl}^{-} \mid \mathrm{Pt}(\text { org })
$$


Table 1. Selected physicochemical and electroanalytical parameters for $\mathrm{CTX}^{+}$.

\begin{tabular}{|c|c|c|c|c|c|c|c|c|c|}
\hline Analyte & $\mathrm{z}$ & $p K a_{1}$ & $p K a_{2}$ & $\mathrm{D}\left[\mathrm{cm}^{2} \mathrm{~s}^{-1}\right]_{\mathrm{aq} \rightarrow \mathrm{org}}{ }^{\mathrm{a}}$ & $\mathrm{D}\left[\mathrm{cm}^{2} \mathrm{~s}^{-1}\right]_{\mathrm{org} \rightarrow \mathrm{aq}}^{\mathrm{a}}$ & $\log P_{\text {water/octanol }}^{C T X}$ & $\log P_{\text {water } / D C E}^{C T X+} \mathrm{b}$ & $\Delta_{\text {org }}^{a q} \Phi^{\prime}[\mathrm{mV}]$ & $\begin{array}{l}\Delta G^{\prime}, a q \rightarrow \text { org } \\
\left.\mathrm{mol}^{-1}\right]^{\mathrm{c}}\end{array}$ \\
\hline$C T X$ & 1 & $3.42[31]$ & $6.84[31]$ & $2.55 \times 10^{-6}$ & $4.62 \times 10^{-7}$ & 0.64 [33] & -4.48 & 265 & 25.57 \\
\hline
\end{tabular}

${ }^{\mathrm{a}}$ Calculated from the Randles-Ševčík equation [14].

${ }^{\mathrm{b}}$ See Eq. 2

${ }^{\mathrm{c}}$ See Eq. 3

\section{Results and discussion}

\section{macroITIES studies}

At first, electrochemical behavior of CTX (the inset - Fig 1A) was studied at the macroITIES with CV and ACV. Chosen CVs recorded at macroITIES for increasing concentrations of $\mathrm{CTX}^{+}$(always initially present in the aqueous phase) are shown in Fig. 1A. When dissolved in $10 \mathrm{mM} \mathrm{HCl}$ solution ( $\mathrm{pH}$ set to 2) CTX is almost fully protonated $\left(\mathrm{p} K_{a 1}=\right.$ 3.42) [31]. Based on its structure inspection (inset of Fig. 1C), we have concluded that at given $\mathrm{pH}, \mathrm{CTX}$ should exist mostly in a cationic form (concentration fraction of cationic form $\sim 96 \%$, see Fig. S1) with a delocalized positive charge located in between primary amine and nitrogen atom from the aminothiazole heterocycle. The carboxylate anions located on the opposite side of the CTX structure will be neutral. As such, positively charged CTX $\left(\mathrm{CTX}^{+}\right)$molecules may undergo the interfacial transport between the aqueous and the organic phases. During voltammetric studies the LLI was polarized from less to more positive potentials on the forward scan giving positive currents being related to the $\mathrm{CTX}^{+}$transfer from the aqueous to the organic phase. As can be seen in Fig. 1A, the observed process was reversible with the forward and reversed current being close to unity and the peak-to-peak separation $\left(\Delta E_{p}\right)$ extrapolated to $56 \mathrm{mV}$ (see the intercept of Fig. S2 showing the increasing peak-to-peak separation plotted in function of the $\mathrm{CTX}^{+}$concentration). The latter value is close to the theoretical $59 \mathrm{mV} \cdot \mathrm{z}^{-1}(z=1)$, and it points out that the CTX molecule is mono-charged. From the slope of the linear dependency of the signal current $\left(I_{s}\right)$ plotted against voltammetric scan rate $(v)$ (Fig. S3) and the Randles-Ševčík equation, we have calculated the aqueous and the organic diffusion coefficients $(D)$. Obtained values were equal to $D_{a q \rightarrow o r g}=2.55 \times 10^{-6} \mathrm{~cm}^{2} \cdot \mathrm{s}^{-1}$ and $D_{\text {org } \rightarrow a q}$ $=4.62 \times 10^{-7} \mathrm{~cm}^{2} \cdot \mathrm{s}^{-1}$. Another parameter that can be determined from CVs is the formal Galvani potential of the ion transfer $\left(\Delta_{\text {org }}^{a q} \Phi^{\prime}\right)$. This parameter is closely related to the hydrophobicity/hydrophilicity of studied molecule. For cationic species, the higher value of the $\Delta_{o r g}^{a q} \Phi^{\prime}$ indicate their greater hydrophilicity [16]. The $\Delta_{\text {org }}^{a q} \Phi^{\prime}$ can be further used (Eq. 2) to calculate the formal water - 1,2-DCE partition coefficient $\left(\log P_{\text {water } / D C E}^{C T X+}\right)$ [32]: $\log _{\text {water } / D C E}^{C T X+}=-\frac{\Delta_{\text {org }}^{a q} \boldsymbol{\Phi}^{\prime} z_{i} F}{2.303 R T}$

where $\Delta_{\text {org }}^{a q} \Phi^{\prime}$, the formal Galvani potential of the ion transfer reaction (in $\mathrm{V}$ ); $z_{i}$, charge of the studied molecule; $F$, the Faraday constant $\left(96485 \mathrm{C} \cdot \mathrm{mol}^{-1}\right) ; R$, the gas constant (8.314 $\mathrm{J} \mathrm{mol}^{-1} \cdot \mathrm{K}^{-1}$ ); and $T$, the temperature $(298 \mathrm{~K})$. The calculated $\log P_{\text {water } / D C E}^{C T X+}$ for $\mathrm{CTX}^{+}$is equal to -4.48 which points out high hydrophilicity of the analyte, while based on the $\log P_{\text {water/octanol }}^{C T X}=0.64$ available in the veterinary substances database [33], it can be stated that CTX is a weakly hydrophobic compound. Finally, the $\Delta_{\text {org }}^{a q} \Phi^{\prime}$ was used to determine the formal Gibbs free energy of the ion transfer interfacial reaction $\left(\Delta G^{\prime}, a q \rightarrow\right.$ org $)$, according to Eq. 3:

$\Delta G^{\prime, a q \rightarrow o r g}=z_{i} F \Delta_{\text {org }}^{a q} \Phi^{\prime}$

All physicochemical and electroanalytical parameters determined for $\mathrm{CTX}^{+}$are collected and summarized in Table 1.

Recently, Suárez-Herrera and Scanlon [34] applied ACV technique to quantitatively analyze simple ion transfer reactions across the electrified LLI. Measurements in AC voltammetry technique are based on the registration of impedance spectra and then converting them to analytical signals. The employment of electrochemical impedance spectroscopy (EIS) allows for the complete elimination of the capacitive current and thus a significant improvement of the sensitivity of the applied technique. In this work, we have applied the optimized ACV procedure for the determination of $\mathrm{CTX}^{+}$at the macroITIES. Figure $2 \mathrm{~A}$ shows the ACV curves recorded at the polarized $10 \mathrm{mM} \mathrm{HCl} \| 1,2-\mathrm{DCE}$ interface in the conventional macroITIES cell (Scheme 1) under conditions described in the "Apparatus" section. Figure $2 \mathrm{~B}$ and $\mathrm{C}$ represent the calibration curve exhibiting two linear dynamic ranges, first from 5.00 to $25.00 \mu \mathrm{M}$ and second from 25.00 to $400.0 \mu \mathrm{M}$. The existence of two slopes defined by a signal originating only from a simple ion transfer reaction is unlikely, and hence, we deduced that $\mathrm{CTX}^{+}$ may undergo weak adsorption process to the ITIES leading to its interfacial preconcentration. The LOD $(1.19 \mu \mathrm{M})$ and LOQ $(3.98 \mu \mathrm{M})$ values for $\mathrm{CTX}^{+}$were calculated from the calibration curve liner fit parameters using $L O D=3 \times \mathrm{SD}_{\mathrm{b}} / \mathrm{a}$ 
Fig. 2. A Alternating current voltammograms (ACVs) recorded for increasing concentration of $\mathrm{CTX}^{+}$. Two dynamic linear ranges (LDRs) are recorded: (0) blank, $\mathrm{LDR}_{1}$ : (1) 5.00 ; (2) 7.50 ; (3) 10.00 ; (4) 15.00 ; (5) 20.00 ; (6) 25.00 ; $\mathrm{LDR}_{2}$ : (6) 25.00; (7) 50.00; (8) 100.0 ; (9) 150.0 ; (10) 200.0; (11) 300.0 ; (12) $400.0 \mu \mathrm{M}$. B The inset presents the corresponding calibration curve for the $\mathrm{LDR}_{1}$. C The corresponding signal intensities plotted in a function of the $\mathrm{CTX}^{+}$concentration. Conditions: $f=1 \mathrm{~Hz}, E$ $=10 \mathrm{mV}$, and $\Delta E=10 \mathrm{mV}$.
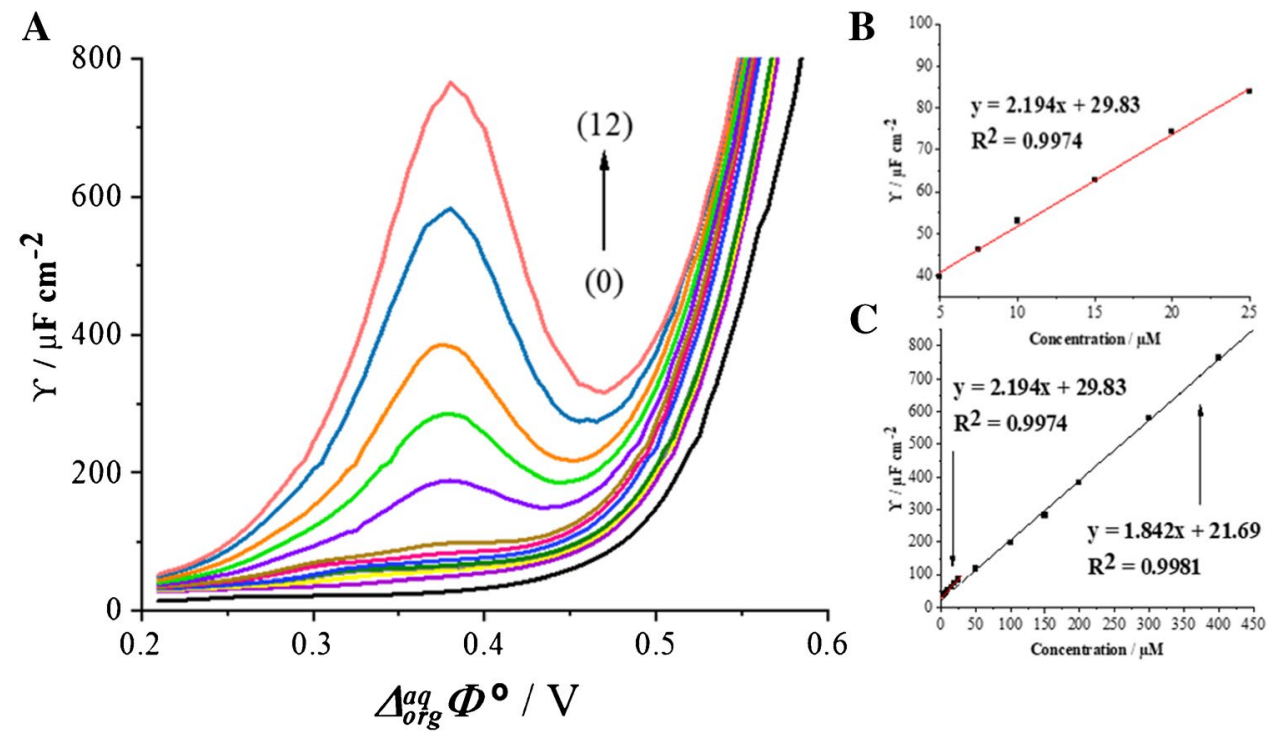

and $L O Q=10 \times \mathrm{SD}_{\mathrm{b}} / \mathrm{a}(S D$, the standard deviation; $a$, slope; $b$, intercept), respectively. The values of sensitivities of the $\mathrm{CTX}^{+}$detection using $\mathrm{ACV}$ procedure were taken from the calibration curves and are defined as slopes of the linear fitting. All determined analytical parameters are collected in Table 2.

\section{$\mathrm{CTX}^{+}$detection at $\mu$ ITIES}

Modern analytical procedures should obey the principles defined by the green chemistry philosophy. One of the trends we should all follow is to minimize the consumption of chemicals, especially those that are toxic. The miniaturization of electrochemical systems based on ITIES undoubtedly meets these expectations. Moreover, ITIES downscaling

Table 2. Electroanalytical parameters of $\mathrm{CTX}^{+}$obtained at the macro- and $\mu$ ITIES.

\begin{tabular}{|c|c|c|c|}
\hline \multirow{2}{*}{$\begin{array}{l}\text { ITIES dimensionality } \\
\text { Technique }\end{array}$} & \multicolumn{2}{|l|}{ macroITIES } & \multirow{2}{*}{$\begin{array}{l}\mu \mathrm{ITIES} \\
\mathrm{CV}\end{array}$} \\
\hline & $\mathrm{CV}$ & $\mathrm{ACV}$ & \\
\hline Number of repetitions & 3 & 1 & 3 \\
\hline $\operatorname{LDR}[\mu \mathrm{M}]$ & $21.4-909.1$ & $\begin{array}{l}\text { I } 5.00-25.00 \\
\text { II } 25.00-400.0\end{array}$ & $13.4-476.2$ \\
\hline $\begin{array}{l}\text { Slope }(a) \\
\left(\mathrm{A} \mathrm{M}^{-1}\right) \text { for } \mathrm{CV} \text {-macroITIES } \\
\left(\mathrm{F} \mathrm{cm}^{-2} \mathrm{M}^{-1}\right) \text { for ACV-macroITIES } \\
\left(\mathrm{nA} \mu \mathrm{M}^{-1}\right) \text { for } \mu \text { ITIES }\end{array}$ & $0.14^{\mathrm{aq} \rightarrow \mathrm{org}}-0.12^{\mathrm{org} \rightarrow \mathrm{aq}}$ & $\begin{array}{l}\text { I } 2.19 \\
\text { II } 1.84\end{array}$ & $0.003^{\mathrm{aq} \rightarrow \mathrm{org}}-0.004^{\mathrm{org} \rightarrow \mathrm{aq}}$ \\
\hline Standard error of slope $\left(S E_{a}\right)^{[\mathrm{a}]}$ & $0.00^{\mathrm{aq} \rightarrow \mathrm{org}} 0.00^{\mathrm{org} \rightarrow \mathrm{aq}}$ & $\begin{array}{l}\text { I } 0.06 \\
\text { II } 0.04\end{array}$ & $0.000^{\mathrm{aq} \rightarrow \mathrm{org}} 0.000^{\mathrm{org} \rightarrow \mathrm{aq}}$ \\
\hline $\begin{array}{l}\text { Intercept }(b) \\
(\mu \mathrm{A}) \text { for } \mathrm{CV} \text {-macroITIES } \\
\left(\mu \mathrm{F} \mathrm{cm}{ }^{-2}\right) \text { for ACV-macroITIES } \\
(\mathrm{nA}) \text { for } \mu \text { ITIES }\end{array}$ & $4.852^{\mathrm{aq} \rightarrow \mathrm{org}}-0.805^{\mathrm{org} \rightarrow \mathrm{aq}}$ & $\begin{array}{l}\text { I } 29.83 \\
\text { II } 21.69\end{array}$ & $0.068^{\mathrm{aq} \rightarrow \mathrm{org}}-0.094^{\mathrm{org} \rightarrow \mathrm{aq}}$ \\
\hline Standard error of intercept $\left(S E_{b}\right)^{[a]}$ & $0.568^{\mathrm{aq} \rightarrow \mathrm{org}} 0.970^{\mathrm{org} \rightarrow \mathrm{aq}}$ & $\begin{array}{l}\text { I } 0.872 \\
\text { II } 7.723\end{array}$ & $0.025^{\mathrm{aq} \rightarrow \mathrm{org}} 0.022^{\mathrm{org} \rightarrow \mathrm{aq}}$ \\
\hline Coefficient of determination $\left(R^{2}\right)$ & $0.9993^{\mathrm{aq} \rightarrow \mathrm{org}} 0.9970^{\mathrm{org} \rightarrow \mathrm{aq}}$ & $\begin{array}{l}\text { I } 0.9974 \\
\text { II } 0.9981\end{array}$ & $0.9939^{\mathrm{aq} \rightarrow \mathrm{org}} 0.9965^{\text {org } \rightarrow \mathrm{ac}}$ \\
\hline $\operatorname{LOD}(\mu \mathrm{M})^{[\mathrm{b}]}$ & $3.53^{\mathrm{aq} \rightarrow \mathrm{org}} 2.71^{\mathrm{org} \rightarrow \mathrm{aq}}$ & 1.19 & $1.46^{\mathrm{aq} \rightarrow \mathrm{org}} 2.22^{\mathrm{org} \rightarrow \mathrm{aq}}$ \\
\hline $\operatorname{LOQ}(\mu \mathrm{M})^{[\mathrm{c}]}$ & $11.76^{\mathrm{aq} \rightarrow \mathrm{org}} 9.03^{\mathrm{org} \rightarrow \mathrm{aq}}$ & 3.98 & $4.86^{\mathrm{aq} \rightarrow \operatorname{org}} 7.39^{\text {org } \rightarrow \mathrm{aq}}$ \\
\hline
\end{tabular}

${ }^{[\mathrm{a}]} S E=S D / n^{1 / 2} ;{ }^{[\mathrm{b}]} L O D=3 \mathrm{SD}_{\mathrm{b}} / \mathrm{a} ;{ }^{\left[{ }^{[c]}\right.} L O Q=10 \mathrm{SD}_{\mathrm{b}} / \mathrm{a}$.

a, slope; and b, intercept 
Fig. 3. A Representative CVs recorded for increasing $\mathrm{CTX}^{+}$ concentrations of (1) 13.3; (2) 26.6; (3) 49.8; (4) 82.6; (5) 147.8 ; (6) 228.0; (7) 353.7; (8) $476.2 \mu \mathrm{M}$; and blank (0) in $10 \mathrm{mM} \mathrm{HCl}(p H=2)$ used as the aqueous phase. The inset presents forward and backward $I_{s}$ intensities plotted in a function of increasing $c_{C T X+}$. B The scheme of interfacial mass transfer of $\mathrm{CTX}^{+}$controlled by the hemispherical diffusion. $\mathbf{C}$ The backward $\mathrm{CTX}^{+}$transfer occurring inside the FSTM governed by a linear diffusion. Conditions: $v=20 \mathrm{mV} \mathrm{s}^{-1}$.
A

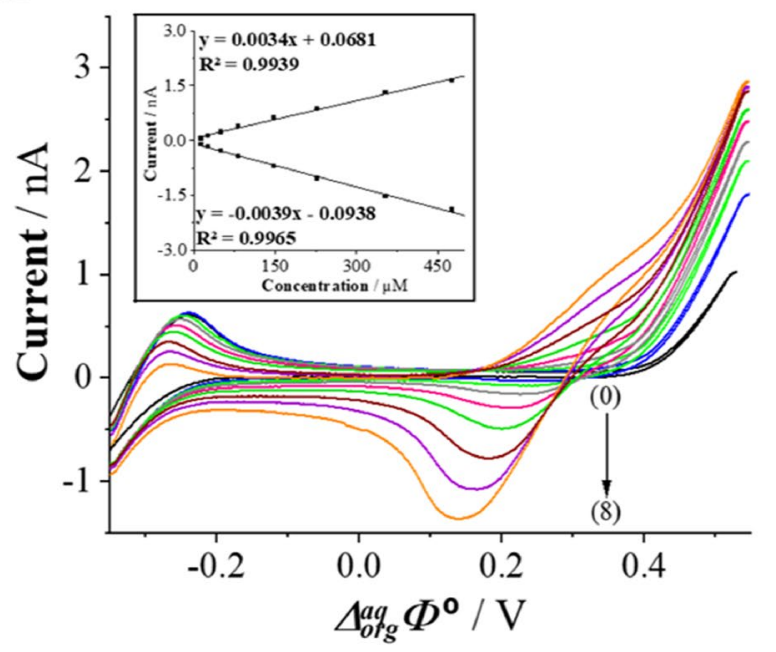

B

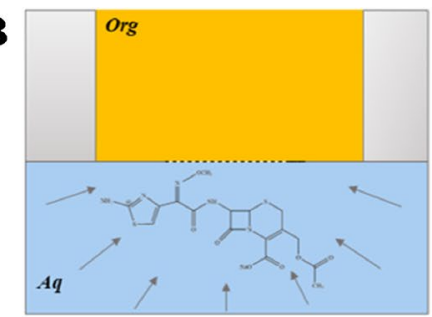

C

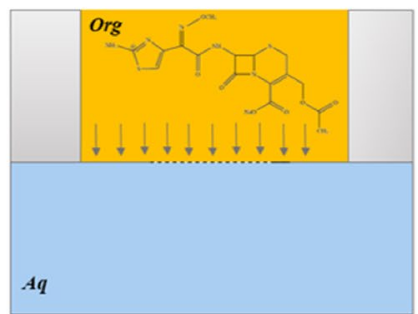

meeting specific geometrical recruitments brings a few additional benefits to electroanalytical sensing: (I) stabilization of the electrified LLI by the employed support (capillary forces and surface wettability of the used supports define the position of the soft junction); (II) improved detection sensitivity of the voltammetric methods (shape of the diffusion zones established above miniaturized LLI enhances the mass transport from the bulk solution to the polarizable junction); and (III) better analytical performance in terms of LOD and LOQ (reduction of the electroactive surface area $=$ smaller capacitive current) $[27,35]$. Therefore, in this work, we have used the FSTM as a polarized LLI support and further applied resulting platform in $\mathrm{CTX}^{+}$detection.

The $\mu$-devices after preparation and characterization were employed to investigate the interfacial behavior of $\mathrm{CTX}^{+}$in $10 \mathrm{mM} \mathrm{HCl}$ solution $(p H=2)$. To evaluate the utility of $\mathrm{CV}$ procedure for $\mathrm{CTX}^{+}$determination at the polarized $\mu \mathrm{ITIES}$, $\mathrm{CTX}^{+}$concentration $\left(c_{\mathrm{CTX}+}\right)$ dependency was recorded (Fig. 3A), and the corresponding calibration curves of $I_{s} v s$. $c_{C T X+}$ were plotted (the inset of Fig. 3A). The asymmetric shape of recorded voltammograms is caused by the coexistence of a hemispherical $\left(\mathrm{CTX}^{+}\right.$transfer from the aqueous to the organic phase, backward scan, Fig. 3B) and linear diffusion $\left(\mathrm{CTX}^{+}\right.$transfer from the organic to the aqueous phase, forward scan, Fig. 3C) and on each side of the LLI. Such behavior is described in other published works [14, 27]. The signal limiting the potential window on the less positive potential window side $(\sim-0.25 \mathrm{~V})$ originate from the interfacial transfer of $\mathrm{Cl}^{-}$anions or BTPPA ${ }^{+}$cations $\left(\mathrm{Cl}^{-}\right.$ transfer from the aqueous to the organic phase or BTTPA ${ }^{+}$ from the organic to the aqueous phase is expected to be recorded as the negative current). Calibration curve was linear within the entire studied concentration range, this is from 13.32 to $476.2 \mu \mathrm{M}$, for both the positive and negative signal intensities. The calculated LOD values for the forward and backward signal currents are equal to 1.5 and $2.2 \mu \mathrm{M}$, respectively. Remaining determined analytical parameters, LOQs, and sensitivities are summarized in Table 2.

\section{Real sample analysis}

To verify the applicability of the developed method, $\mathrm{CTX}^{+}$ was determined in a spiked tap and mineral water samples using $\mathrm{CV}$ and $\mathrm{ACV}$ techniques (Fig. 4). The $\mathrm{pH}$ of collected water samples was first adjusted with a $1 \mathrm{M} \mathrm{HCl}$ solution until $p H=2$ was reached. Next, appropriate aliquots of $\mathrm{CTX}^{+}$stock solutions were added. The samples did not require any further purification to remove salts or any other contaminants. The chemical composition of real tap and mineral water samples includes inorganic cations that may undergo interfacial ion transfer further affecting the positive current values limiting the potential window on more positive potential site. We assume that the existence of additional cations in the aqueous phase is a consequence of overlaid positive current signals recorded for real samples shown in Fig. 4C/D. As such, the backward signals were analyzed for $\mathrm{CTX}^{+}$quantification.

\section{AC voltammetry measurements}

The ACV studies were performed in a traditional macroITIES cell (Scheme 1), wherein the aqueous phase compartment of the cell was filled with $3.50 \mathrm{~mL}$ of a sample (mineralor tap water). Figure 4 presents the ACVs recorded upon addition of the appropriate aliquot of the stock solution of $\mathrm{CTX}^{+}$to the still mineral water (Fig. 4A) and tap water (Fig. 4B) samples. The analytical signals (positive or negative currents) increased linearly with $\mathrm{CTX}^{+}$concentration in two linear dynamic ranges of 5.00 to $25.00 \mu \mathrm{M}$ and 25.00 to $400.0 \mu \mathrm{M}$ in both samples. The LODs and LOQs 
A

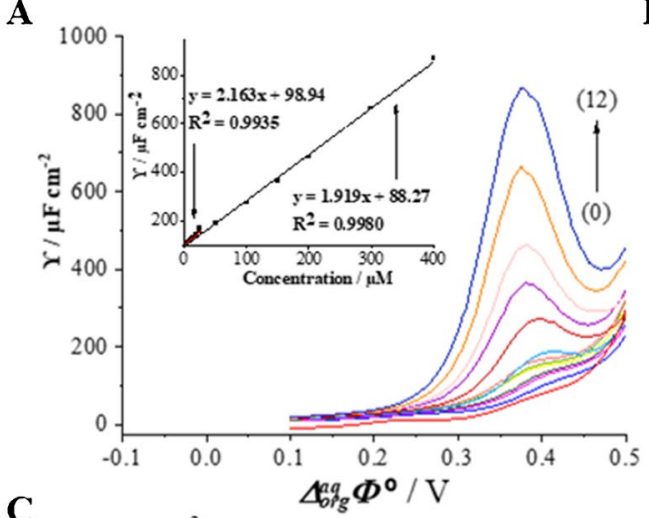

C

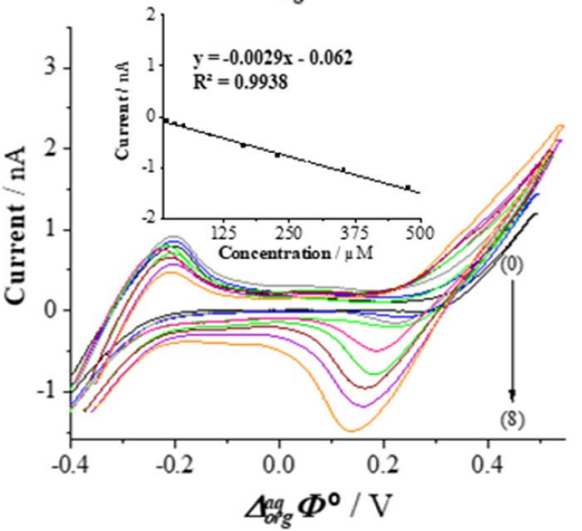

B

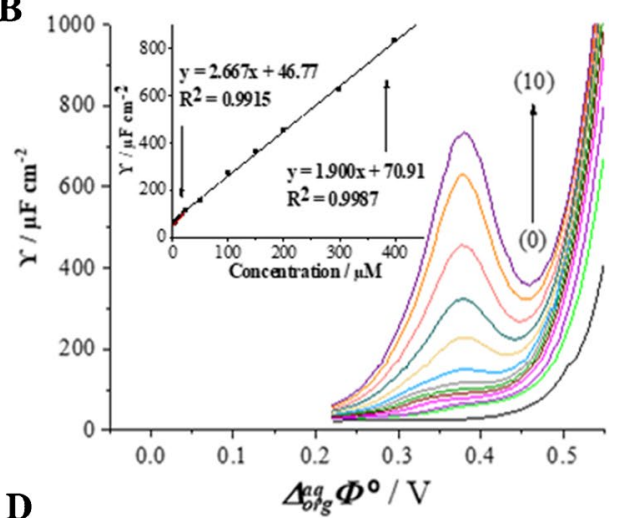

D

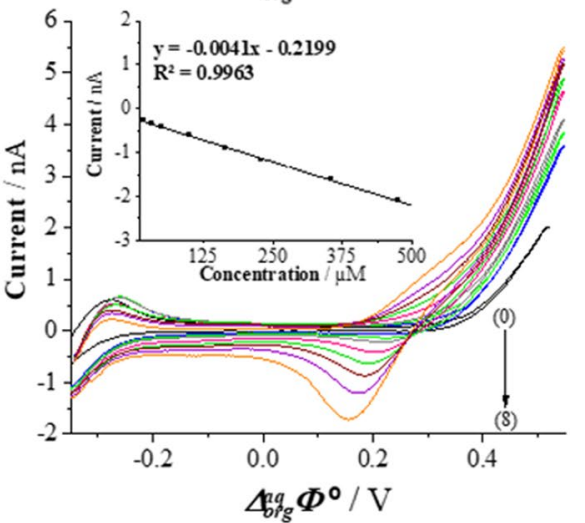

Fig. 4. A, B ACVs recorded at macroITIES for increasing $\mathrm{CTX}^{+}$ concentrations added to still mineral (A) and tap water $(\mathbf{B})$ together with the corresponding calibration curves showing the intensities of the signal plotted in function of the increasing $\mathrm{CTX}^{+}$concentrations within the range of (1) 5.00 ; (2) 7.50; (3) 10.00; (4) 15.00; (5) 20.00; (6) 25.00 ; (7) 50.00 ; (8) 100.0; (9) 150.0; (10) 200.0; (11) 300.0; (12) $400.0 \mu \mathrm{M}$; and blank (0). Conditions ACV: $f=1 \mathrm{~Hz}, E=10 \mathrm{mV}$ and

were calculated from the calibration curves and first LDR. The calculated LODs values for determination of $\mathrm{CTX}^{+}$in a mineral and tap water samples are equal to 1.9 and $2.1 \mu \mathrm{M}$, respectively (the lowest detected concentration was equal to $1.00 \mu \mathrm{M}$ and was beyond the LDR). Given obtained output, described procedure is suitable for $\mathrm{CTX}^{+}$determination in real samples.

\section{$\mu$ ITIES measurements}

The utility of the elaborated CV procedure at the $\mu$ ITIES was also checked in determination of $\mathrm{CTX}^{+}$in a still mineral (Fig. 4C) and tap (Fig. 4D) water samples. The CV measurements were conducted at $\mu$ ITIES platform (Scheme 2) immersed to the aqueous phase having a total volume of $15.00 \mathrm{~mL}$ (mineral or tap water). The calibration curves were constructed only based on the backward (negative) peak current because the signals of $\mathrm{CTX}^{+}$transfer from the aqueous to the organic phase were overlapped with the proton transfer. As can be seen from the Fig. 4, the corresponding
$\Delta E=10 \mathrm{mV}, p H=2 . \mathbf{C}, \mathbf{D} \mathrm{CV}$ s recorded at $\mu$ ITIES for increasing $\mathrm{CTX}^{+}$concentrations added to still mineral $(\mathbf{C})$ and tap water $(\mathbf{D})$ together with the corresponding calibration curves showing the intensities of the backward (negative) currents plotted in function of the increasing $\mathrm{CTX}^{+}$concentrations within the range of (1) 16.64; (2) 33.22 ; (3) 49.75; (4) 99.01 ; (5) 163.9; (6) 228.0; (7) 322.58; (8) 476.2 $\mu \mathrm{M}$; and blank (0). Conditions $\mathrm{CV}$ : scan rate $=20 \mathrm{mV} \cdot \mathrm{s}^{-1}, \mathrm{pH}=2$.

calibration curve is linear within the dynamic range of 16.6-476.2 $\mu \mathrm{M} \mathrm{CTX}^{+}$concentrations in both samples. The LODs values for $\mathrm{CTX}^{+}$determination in a tap and mineral water samples are calculated to be 5.57 and $9.70 \mu \mathrm{M}$, respectively. All obtained analytical parameters for $\mathrm{CTX}^{+}$determination in real samples by means of ACV and CV techniques were collected in Table S1 (see the electronic supporting information).

\section{Conclusion}

This work reports on quantitative analysis performed by two electrochemical techniques: cyclic voltammetry (CV) and alternating current voltammetry (ACV), for the determination of the antibiotic - cefotaxime in model - still mineral and tap water samples. The output of the ACV as compared with CV method applied to a macroITIES provided better analytical parameters (lower LODs and LOQs values). Although giving better performance, ACV technique 
requires further data processing and is more time-consuming. The application of the $\mu$ ITIES-based setup for the real sample analysis additionally provided improved stability of the soft junction supported with a solid support, reduced volume of the organic phase, and assured compact size of the sensing set-up. Cefotaxime detection at $\mu$ ITIES with $\mathrm{CV}$ provided improved electroanalytical parameters comparable to these obtained with ACV at macroITIES. Hence, miniaturized systems were further applied for cefotaxime detection in real samples. Since we did not observe any interference of the real sample matrix during cefotaxime detection, these did not require any further preparation.

Supplementary Information The online version contains supplementary material available at https://doi.org/10.1007/s00604-021-05072-w.

Funding This study is financially supported by the National Science Center (NCN) in Cracow, Poland (Grant no. UMO-2018/29/N/ ST4/01054), and Embassy of France in Poland.

\section{Declarations}

Conflict of interest The authors declare no competing interests.

Open Access This article is licensed under a Creative Commons Attribution 4.0 International License, which permits use, sharing, adaptation, distribution and reproduction in any medium or format, as long as you give appropriate credit to the original author(s) and the source, provide a link to the Creative Commons licence, and indicate if changes were made. The images or other third party material in this article are included in the article's Creative Commons licence, unless indicated otherwise in a credit line to the material. If material is not included in the article's Creative Commons licence and your intended use is not permitted by statutory regulation or exceeds the permitted use, you will need to obtain permission directly from the copyright holder. To view a copy of this licence, visit http://creativecommons.org/licenses/by/4.0/.

\section{References}

1. Samanidou VF, Tsochatzis ED, Papadoyannis IN (2008) HPLC determination of cefotaxime and cephalexine residues in milk and cephalexine in veterinary formulation. Microchim Acta 160:471475. https://doi.org/10.1007/s00604-007-0820-1

2. Salem H, Samir E (2018) Determination of cefotaxime, cefoperazone, ceftazidime and cefadroxil using surface plasmon resonance band of silver nanoparticles. Br J Pharm Sci 54:1-9. https://doi. org/10.1590/s2175-97902018000317565

3. Yang G, Zhao F, Zeng B (2014) Electrochemical determination of cefotaxime based on a three-dimensional molecularly imprinted film sensor. Biosens Bioelectron 53:447-452. https://doi.org/10. 1016/j.bios.2013.10.029

4. Zhang F, Gu S, Ding Y et al (2013) Electrooxidation and determination of cefotaxime on Au nanoparticles/poly (L-arginine) modified carbon paste electrode. J Electroanal Chem 698:25-30. https://doi.org/10.1016/j.jelechem.2013.03.010

5. Arabsorkhi B, Sereshti H (2018) Determination of tetracycline and cefotaxime residues in honey by micro-solid phase extraction based on electrospun nanofibers coupled with HPLC. Microchem J 140:241-247. https://doi.org/10.1016/j.microc.2018.04.030

6. Aleksić MM, Kapetanović V, Atanacković J et al (2008) Simultaneous determination of cefotaxime and desacetylcefotaxime in real urine sample using voltammetric and high-performance liquid chromatographic methods. Talanta 77:131-137. https://doi.org/10. 1016/j.talanta.2008.05.047

7. Burrer A, Findeisen P, Jäger E et al (2015) Rapid detection of cefotaxime-resistant Escherichia coli by LC-MS. Int J Med Microbiol 305:860-864. https://doi.org/10.1016/j.ijmm.2015.08.004

8. Chen D, Wang H, Zhang Z et al (2011) Chemiluminescence determination of cefotaxime sodium with flow-injection analysis of cerium (IV)-rhodamine $6 \mathrm{G}$ system and its application to the binding study of cefotaxime sodium to protein with on-line microdialysis sampling. Spectrochim Acta - Part A Mol Biomol Spectrosc 78:553-557. https://doi.org/10.1016/j.saa.2010.10. 014

9. Aleksić MM, Kapetanović V (2006) Voltammetric behavior and square-wave voltammetric determination of cefotaxime in urine. J Electroanal Chem 593:258-266. https://doi.org/10.1016/j.jelec hem.2006.06.011

10. Bottari F, Blust R, De Wael K (2018) Bio(inspired) strategies for the electro-sensing of $\beta$-lactam antibiotics. Curr Opin Electrochem 10:136-142. https://doi.org/10.1016/j.coelec.2018.05.015

11. Karabozhikova V, Tsakova V (2019) Electroanalytical determination of caffeic acid - factors controlling the oxidation reaction in the case of PEDOT-modified electrodes. Electrochim Acta 293:439-446. https://doi.org/10.1016/j.electacta.2018.10.067

12. Gao G, Vecitis CD (2013) Electrocatalysis aqueous phenol with carbon nanotubes networks as anodes: electrodes passivation and regeneration and prevention. Electrochim Acta 98:131-138. https://doi.org/10.1016/j.electacta.2013.02.127

13. Chen R, Xu K, Shen M (2020) Electrochimica Acta Avocado oil, coconut oil, walnut oil as true oil phase for ion transfer at nanoscale liquid /liquid interfaces. Electrochim Acta 357:136788. https://doi.org/10.1016/j.electacta.2020.136788

14. Rudnicki K, Sobczak K, Borgul P et al (2021) Determination of quinine in tonic water at the miniaturized and polarized liquid - liquid interface. Food Chem 364:130417. https://doi.org/10. 1016/j.foodchem.2021.130417

15. Alvarez De Eulate E, Strutwolf J, Liu Y et al (2016) An electrochemical sensing platform based on liquid-liquid microinterface arrays formed in laser-ablated glass membranes. Anal Chem 88:2596-2604. https://doi.org/10.1021/acs.analchem.5b03091

16. Rudnicki K, Poltorak L, Skrzypek S, Sudhölter EJR (2019) Ion transfer voltammetry for analytical screening of fluoroquinolone antibiotics at the water - 1,2-dichloroethane interface. Anal Chim Acta. https://doi.org/10.1016/j.aca.2019.07.065

17. Poltorak L, Rudnicki K, Kolivoška V et al (2021) Electrochemical study of ephedrine at the polarized liquid-liquid interface supported with a 3D printed cell. J Hazard Mater 402:123411. https:// doi.org/10.1016/j.jhazmat.2020.123411

18. Riva JS, Cámara CI, Juarez AV, Yudi LM (2014) Electrochemical behaviour of cationic polyelectrolytes at a polarized liquid/liquid interface. J Appl Electrochem 44:1381-1392. https://doi.org/10. 1007/s10800-014-0747-2

19. Liu S, Li Q, Shao Y (2011) Electrochemistry at micro- and nanoscopic liquid/liquid interfaces. Chem Soc Rev 40:2236-2253. https://doi.org/10.1039/c0cs00168f

20. Xie L, Huang X, Lin X, Su B (2017) Nanoscopic liquid/liquid interface arrays supported by silica isoporous membranes: transmembrane resistance and ion transfer reactions. J Electroanal Chem 784:62-68. https://doi.org/10.1016/j.jelechem.2016.12.007

21. Poltorak L, Morakchi K, Herzog G, Walcarius A (2015) Electrochemical characterization of liquid-liquid micro-interfaces 
modified with mesoporous silica. Electrochim Acta 179:9-15. https://doi.org/10.1016/j.electacta.2015.01.129

22. Borgul P, Rudnicki K, Chu L et al (2020) Layer-by-layer (LbL) assembly of polyelectrolytes at the surface of a fiberglass membrane used as a support of the polarized liquid-liquid interface. Electrochim Acta 363:137215. https://doi.org/10.1016/j.electacta. 2020.137215

23. Stockmann TJ, Olaya AJ, Méndez MA et al (2011) Evaluation of Gibbs energy of dioxouranium transfer at an electrified liquidlliquid interface supported on a microhole. Electroanalysis 23:2677-2686. https://doi.org/10.1002/elan.201100401

24. Scanlon MD, Strutwolf J, Blake A et al (2010) Ion-transfer electrochemistry at arrays of nanointerfaces between immiscible electrolyte solutions confined within silicon nitride nanopore membranes. Anal Chem 82:6115-6123. https://doi.org/10.1021/ac100 8282

25. Poltorak L, Sudhölter EJR, de Puit M (2019) Electrochemical cocaine (bio)sensing From solid electrodes to soft junctions. TrAC - Trends Anal Chem 114:48-55. https://doi.org/10.1016/j. trac.2019.02.025

26. Iwai NT, Kramaric M, Crabbe D, et al (2018) GABA Detection with nano-ITIES pipet electrode: a new mechanism, water/DCEoctanoic acid interface. Anal Chem 90(5):3067-3072. https://doi. org/10.1021/acs.analchem.7b03099

27. Rudnicki K, Poltorak L, Skrzypek S, Sudhölter EJR (2018) Fused silica microcapillaries used for a simple miniaturization of the electrified liquid-liquid interface. Anal Chem 90:7112-7116. https://doi.org/10.1021/acs.analchem.8b01351

28. Kowalewska K, Sipa K, Leniart A et al (2020) Electrochemistry at the liquid-liquid interface rediscovers interfacial polycondensation of nylon-6,6. Electrochem Commun 115:106732. https://doi.org/ 10.1016/j.elecom.2020.106732

29. Samec Z (2004) Electrochemistry at the interface between two immiscible electrolyte solutions (IUPAC technical report). Pure Appl Chem 76:2147-2180

30. Lu G, Despas C, Liu L, Herzog G (2020) Ametryn detection by proton assisted transfer at a single micro-interface between two immiscible electrolyte solutions. J Electroanal Chem 877:114745. https://doi.org/10.1016/j.jelechem.2020.114745

31. https://go.drugbank.com/. Accessed 18 Aug 2021

32. Poltorak L, Sudhölter EJR, de Smet LCPM (2017) Effect of charge of quaternary ammonium cations on lipophilicity and electroanalytical parameters: task for ion transfer voltammetry. J Electroanal Chem 796:66-74. https://doi.org/10.1016/j.jelechem.2017.04.051

33. http://sitem.herts.ac.uk/aeru/vsdb/Reports/1940.htm. Accessed 10 Aug 2021

34. Suárez-Herrera MF, Scanlon MD (2020) Quantitative analysis of redox-inactive ions by AC voltammetry at a polarized interface between two immiscible electrolyte solutions. Anal Chem 92:10521-10530. https://doi.org/10.1021/acs.analchem.0c01340

35. van den Brink FTG, Olthuis W, van den Berg A, Odijk M (2015) Miniaturization of electrochemical cells for mass spectrometry. TrAC Trends Anal Chem 70:40-49. https://doi.org/10.1016/J. TRAC.2015.01.014

Publisher's note Springer Nature remains neutral with regard to jurisdictional claims in published maps and institutional affiliations. 